\title{
Condensation of Novec 649 refrigerant in pipe minichannels
}

\author{
Tadeusz Bohdal $^{1}$, Henryk Charun $^{1}$, and Matgorzata Sikora ${ }^{1, *}$ \\ ${ }^{1}$ Koszalin University of Technology, Department of Energy, ul. Racławicka 15-17, PL -75-620 Koszalin, Poland
}

\begin{abstract}
The paper presents the results of experimental investigation of Novec 649 refrigerant condensation in tube minichannels. This is a low-pressure refrigerant. This investigations are basis for flow structures visualization during condensation in pipe minichannels. The local and the average values of pressure drop $(\Delta \mathrm{p} / \mathrm{L})$ and heat transfer coefficient $\alpha$ in the whole range of the changes of vapour quality $(\mathrm{x}=$ $1 \div 0$ ) were calculated. On the basis of the obtained test results there was illustrated the influence of the vapour quality $\mathrm{x}$, the mass flux density $\mathrm{G}$ and the inner diameter of channel $\mathrm{d}$ changes on the studied parameters. These results were compared with the calculation results based on the dependencies of other authors.
\end{abstract}

\section{Introduction}

Due to the development of technologies and miniaturization of power equipment (while increasing their efficiency), compact heat exchangers are very important area of studies around the world. Exchangers of this type are built from mini and microchannels, which results in an increase of heat transfer intensity by a small surface. The minichannels are those channels which hydraulic diameter $d_{h}<3 \mathrm{~mm}$. Especially important in this case are two-phase diabatic flows, with accompanying phase change like condensation or boiling [11].

Two-phase flow phenomena in conventional channels in diabatic conditions are completely different than those received in minichannels. Therefore, the transfer of the results obtained in the field of two-phase flow in conventional channels, to mini- and microchannels is incorrect and causes errors in interpretation of thermal and flow phenomena. It is known that in the small diameter channels significant impact on the mechanism of momentum and energy transport have viscosity and surface tension, while gravity and inertia forces are less important [14]. In the work of Coleman and Garimella [7, 9] was found that for channels with a hydraulic diameter greater than $10 \mathrm{~mm}$, the channel dimension and surface tension didn't significantly influence on flow and thermal parameters. This proves that the experimental investigations of refrigerants condensation in mini and microchannels are very important. Many scientists from around the world conduct research in this area for years.

For example, Fronk and Garimella [8] presented a comparison of modern methods for calculating the heat transfer coefficient and flow resistance in the condensation process in conventional and minichannels. They pointed to the usefulness of computational methods of authors such as: Silver [19], Bell and Ghaly [3],
Thome [23] and Cavallini et al. [5,6]. The proposed methods are based on the analysis of the condensation mechanism in the flow, but their weakness is the degree of complexity of equations.

Zhang et al. [28] in his study presented the results of $\mathrm{R} 22, \mathrm{R} 410 \mathrm{~A}$ and $\mathrm{R} 407 \mathrm{C}$ refrigerant condensation in single circular minichannels with internal diameters of 1.088 and $1.289 \mathrm{~mm}$, with parameters in the ranges of: saturation temperature $\mathrm{T}_{\mathrm{s}}=30-40{ }^{\circ} \mathrm{C}$, mass flux density $\mathrm{G}=300-600 \mathrm{~kg} / \mathrm{m}^{2} \mathrm{~s}$ and vapour quality $\mathrm{x}=0.9-0.1$. As expected, it was found that pressure drops increase when the mass flux density, G, and vapour quality, $x$, increase, but in the range of $\mathrm{x}>0.8$, this influence is much smaller. What is more the influence of the channel diameter and refrigerant type on pressure drops was shown.

Son and Oh [20] presented experimental results of pure R22, R134a and R410A refrigerants pressure drops during condensation in a vertical circular channel with an inner diameter of $1.77 \mathrm{~mm}$ and a length of $1.22 \mathrm{~m}$ for the ranges of mass flux density $\mathrm{G}=450-1050 \mathrm{~kg} /\left(\mathrm{m}^{2} \mathrm{~s}\right)$, and saturation temperature $\mathrm{T}_{\mathrm{s}}=40^{\circ} \mathrm{C}$. The experimental results illustrated the dependence of the vapour quality $\mathrm{x}$, on the pressure drop for R22, R134a and R410A refrigerants in pipe minichannels with an internal diameter of $1.77 \mathrm{~mm}$. It was shown that the pressure drops for R410A are the lowest in the same mass flux density.

Not only internal diameter of the channel have important influence on condensation phenomena. Second very important thing is kind of refrigerant. Rajan [17] showed in his work that R410A refrigerant is more effective than R22 because the heat transfer coefficient for R410A is higher by approximately $30 \%$ at boiling, and, in the same time, the pressure drop is lower by approximately $40 \%$.

Due to the destructive impact of refrigerants from $\mathrm{CFC}$ and HCFC groups on the ozone layer and the

Corresponding author: malgorzata.sikora@tu.koszlin.pl 
intensification of global warming, radical actions were taken in order to eliminate derived chlorinated substances from a common use. The first international agreement which was aimed to protect the environment was the Montreal Protocol [16]. The consequence of this document is the Act on substances that deplete the ozone layer [25] passed by the European Union and ratified by the Polish Parliament. Removed refrigerants are successively replaced with ecological refrigerants having similar physicochemical properties Most of new refrigerants are mixtures. As a replacements of R22 refrigerant are used zeotropic mixtures as: R404A, $\mathrm{R} 407 \mathrm{C}$ and R410A [4, 12]. The most popular homogenous refrigerant $\mathrm{R} 134 \mathrm{a}$ is removed now because of very high global warming potential (GWPR134a = 1430), and companies are looking for new substitutes as a R1234yf or R1234ze [1, 26, 13]. According to the Directive of the European Parliament and the Council of Europe No. 2006/40/EC the use of fluorinated greenhouse gases for which GWP value is greater than 150 is limited in all newly manufactured refrigeration and MAC (Mobile Air Conditioning) systems [1, 24, 26].

What is more, now is a lot of new mixtures as a working fluids and scientists investigate two-phase flow phenomenon with they use. For example, Zhuang and all [29] made experimental investigation of methane condensation in a horizontal smooth tube in range of mass flux density $\mathrm{G}=99-255 \mathrm{~kg} / \mathrm{m}^{2} \mathrm{~s}$. Methane is natural refrigerant with came back to use. Wen and all [27] made numerical investigations on R1234ze(E) and propane condensation in channels with internal diameter $\mathrm{d}=1-4.9 \mathrm{~mm}$. Results of heat transfer and frictional pressure parameters calculations were compared with results for R134a refrigerant. Ghim and Lee in work [10] made an experimental investigations of condensation in ORC of R245fa, Novec 649, HFE7000 refrigerants. Investigations was conducted in straight horizontal channel with internal diameter $\mathrm{d}=7.75 \mathrm{~mm}$ in range of mass flux density $\mathrm{G}=150-700 \mathrm{~kg} / \mathrm{m}^{2} \mathrm{~s}$, vapour quality $\mathrm{x}$ $=0.95-0.05$. Authors showed, that heat transfer coefficient $\alpha$ during condensation is highest for R245fa then HFE 7000 and the lowest for Novec 649.

This work concerns condensation of Novec 649 refrigerant in pipe minichannels. This working fluid is environmentally friendly, its ODP is 0 , GWP 1 and its atmospheric lifetime is about 5 days [1]. This is low pressure refrigerant and is one of most reference fluids for mobile applications [15].

From the given publication review, it can be concluded that the number of publications concerning the condensation of new, environmentally friendly refrigerants in minichannels is not bid enough. There is no clearly preferred method of heat transfer coefficient and pressure drop calculation. There is need of further study of the condensation process of these refrigerants, especially in mini and microchannel. Very interesting will be a investigation of two-phase flow structures for new refrigerants.

\section{Experimental study}

Subject of study was condensation of Novec 649 refrigerant in tubular minichannels made from stainless steel with an internal diameter $\mathrm{d}=0.5,0.7$ and $1.2 \mathrm{~mm}$ Fig. 1shows the view of this kind of minichannels. On fig. 2 are showed example properties of refrigerant Novec 649.

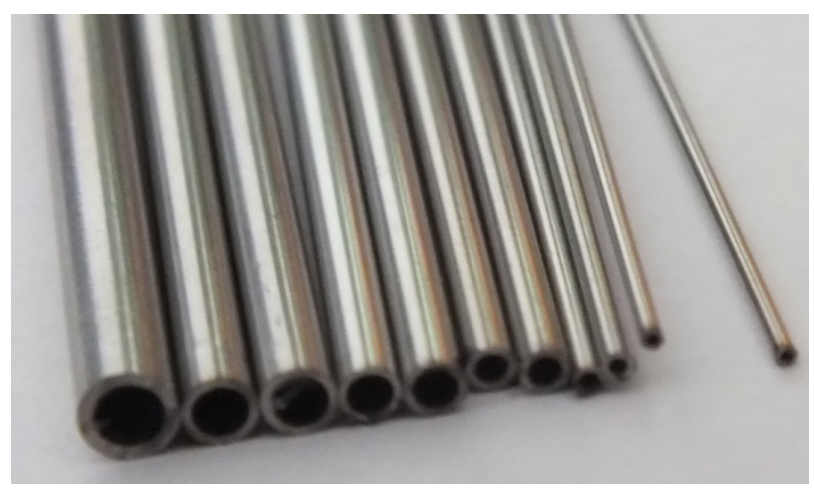

Fig. 1. View of used stainless steel minichannels.

a)

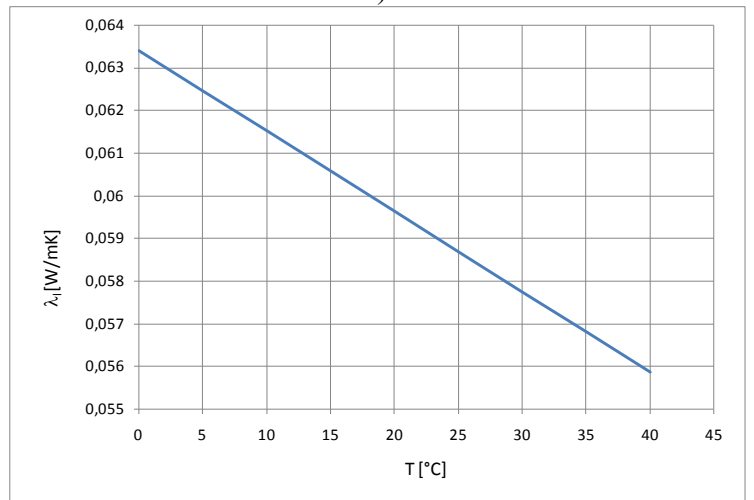

b)

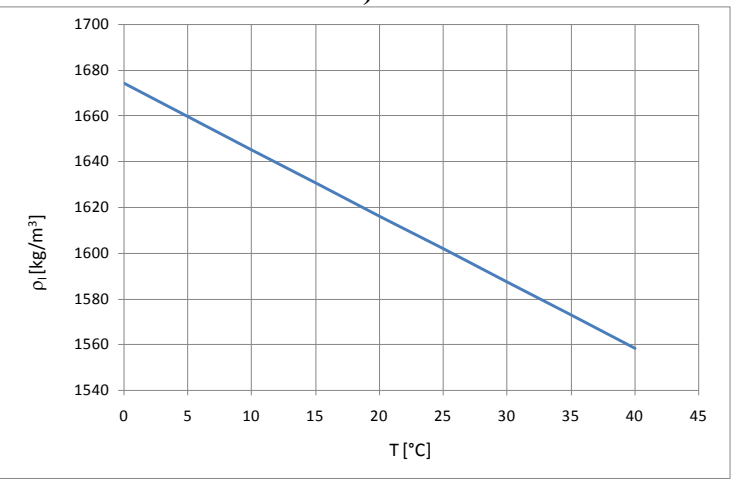

Fig. 2. Dependence of example properties on refrigerant Novec 649 temperature; a) liquid conductivity $\lambda$, b) liquid density $\rho[30]$.

The heat and flow investigations were conducted in terms of parameters:

- inner diameter of minichannel: $\mathrm{d}=0,5-1,2 \mathrm{~mm}$,

- mass flux density: $\mathrm{G}=790 \div 5525 \mathrm{~kg} / \mathrm{m}^{2} \mathrm{~s}$,

- heat flux density: $\mathrm{q}=0 \div 200 \mathrm{~kW} / \mathrm{m}^{2}$,

- saturation temperature: $\mathrm{t}_{\mathrm{s}}=30 \div 70^{\circ} \mathrm{C}$,

- vapor quality: $\mathrm{x}=1 \div 0$. 


\subsection{Test stand}

Schematic diagram of the test stand for thermal - flow and structure visualization researches of two-phase flow during condensation of Novec 649 refrigerant is shown in fig. 3. On the schematic diagram there are listed two sections, named as A and B. Section A were used for thermal and flow experimental investigations of refrigerants condensation in pipe minichannels. The investigation allowed experimental determining of the average and local values of heat transfer coefficient $\alpha$ and flow resistance $\Delta \mathrm{p} / \mathrm{l}$ during condensation.

Section B can be used to visualisation of flow structures during condensation of refrigerants in minichannels.

In fig. 4 is shown real view of heat and flow measurement section, with was cooling by water. The working length of the channel was $\mathrm{L}=0.15 \mathrm{~m}$. For measure temperature of channel wall and cooling water were used K-type thermocouples.

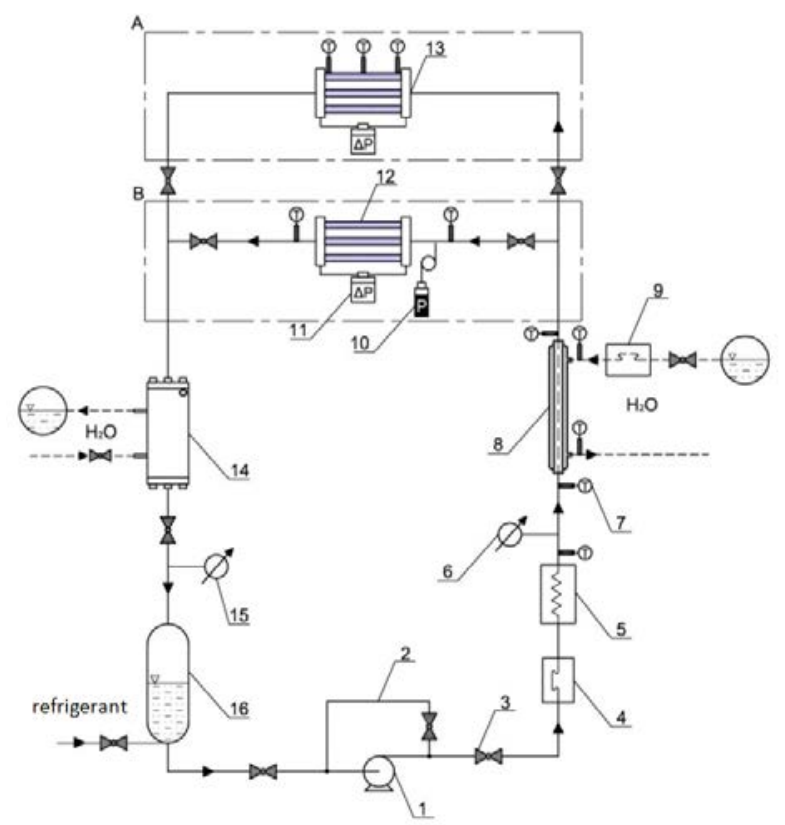

Fig. 3. Schematic diagram of the test stand $A-$ Section for thermal and flow investigations, B - Section for experimental visualization of two-phase flow structures; 1 - ceramic pump, 2 - bypass for the flow control, 3 - valve, 4 - flowmeter for refrigerant, 5 - evaporator, 6 - manometer, 7 - K-type thermocouples, 8 - pre-heat exchanger "pipe in pipe" type , 9 flowmeter for cooling water, 10 - pressure sensor, 11 differential pressure sensor, 12 - horizontal section for visualization, 13 - horizontal section of a heat-flow measurement, 14 - heat exchanger, 15 - manometer, 16 - tank of liquid refrigerant.

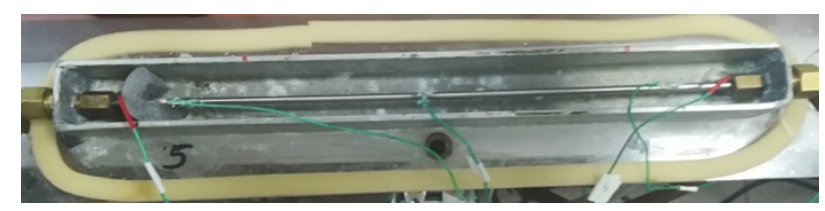

Fig. 4. Real view of heat and flow measurement section.

\subsection{Investigation results}

Fig. 5 and 6 show the thermal and flow characteristics of the Novec 649 refrigerant condensations, for example, in a pipe minichannel with an internal diameter $\mathrm{d}=0.5,0.7$ and $1.2 \mathrm{~mm}$. The provided characteristics illustrate a dependence of the local heat transfer coefficient, $\alpha_{x}$ and local pressure drops, $(\Delta \mathrm{p} / \mathrm{L})_{\mathrm{x}}$ on the vapour quality, $\mathrm{x}$ and the mass flux density, G.

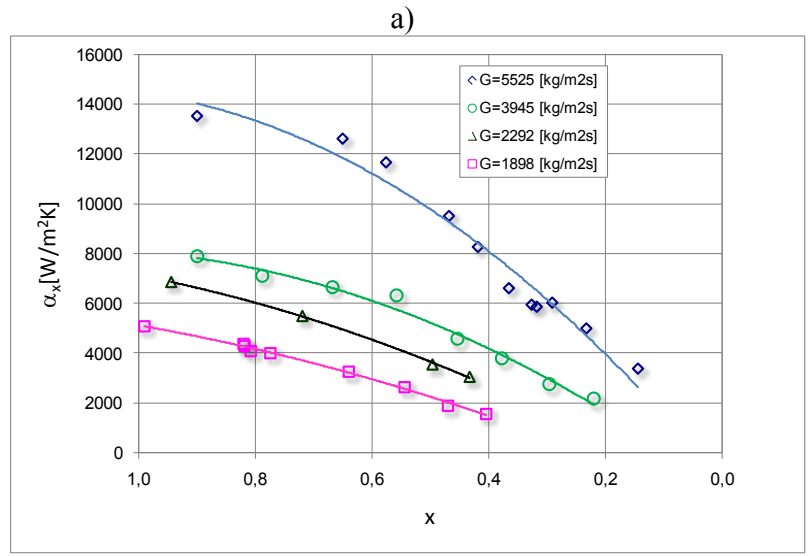

b)

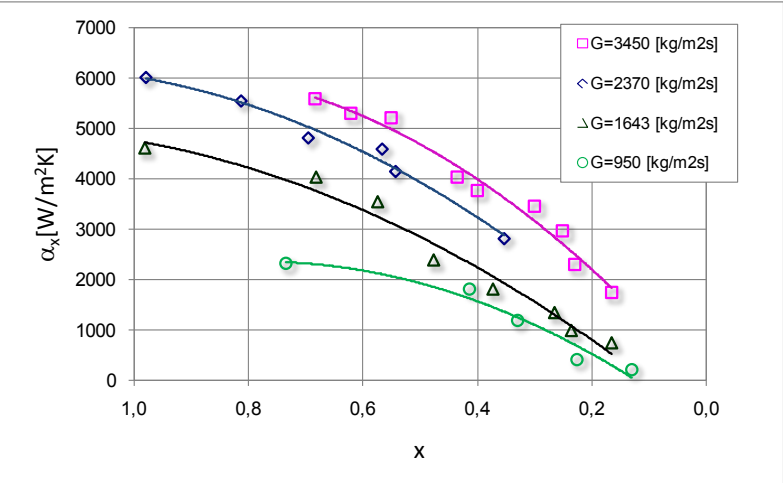

c)

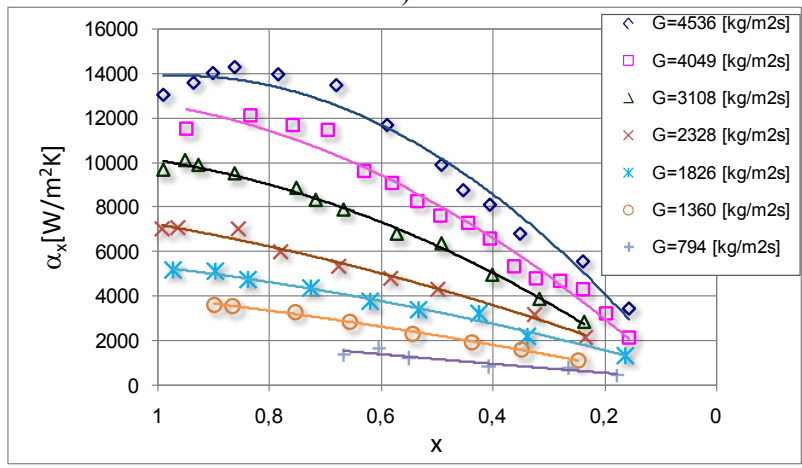

Fig. 5. Local heat characteristics of Novec 649 refrigerant condensation in pipe minichannels: a) $d=0.5 \mathrm{~mm}, b) d=0.7 \mathrm{~mm}$, c) $\mathrm{d}=1.2 \mathrm{~mm}$.

The characteristics of the thermal and flow changes were made for the whole range of vapour quality, from $\mathrm{x}$ $=1$ to $\mathrm{x}=0$. The value of the local heat transfer coefficient for the condensation process initially increases, reaches a maximum value near to $\mathrm{x}=0.8$ and then follows. The reduction of the vapour quality during condensation affect increases the amount of saturated liquid in the two-phase mixture. For the liquid phase, the heat transfer coefficient is smaller than for the two-phase 
mixture, which justifies the decrease in the value of the heat transfer $\alpha_{x}$ coefficient. Reduction of the inner diameter, $d$ of the pipe minichannel enhances the heat transfer in the condensation process.

In fig. 6 are shown similar flow characteristics. They show changes of the local pressure drops, $(\Delta \mathrm{p} / \mathrm{L})_{\mathrm{x}}$, with a decrease of the vapour quality, $x$ of the two-phase mixture. Pressure drops depends on vapour quality like the heat transfer coefficient $\alpha$ Intensification of the heat transfer during condensation, implemented to reduce the minichannel internal diameter, requires an increase in the driving energy of the flowing refrigerant mixture. Proof of this is the increase of pressure drops $(\Delta \mathrm{p} / \mathrm{L})_{\mathrm{x}}$ with a reduction of the minichannel internal diameter.

a)

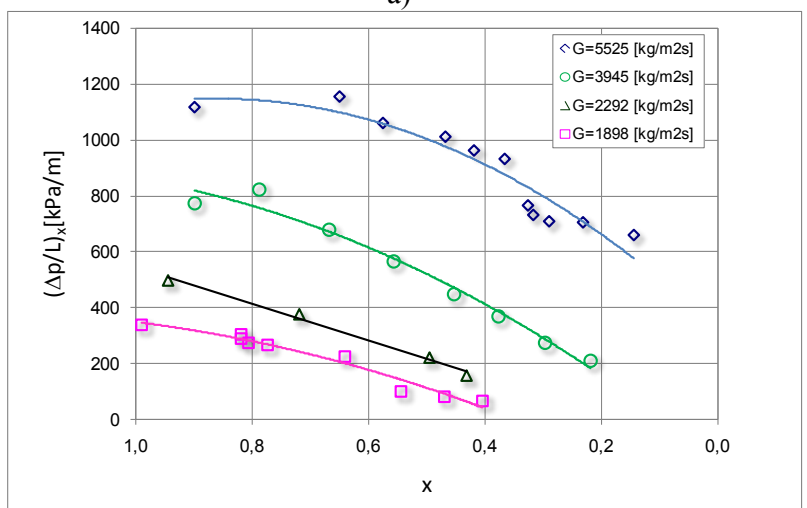

b)

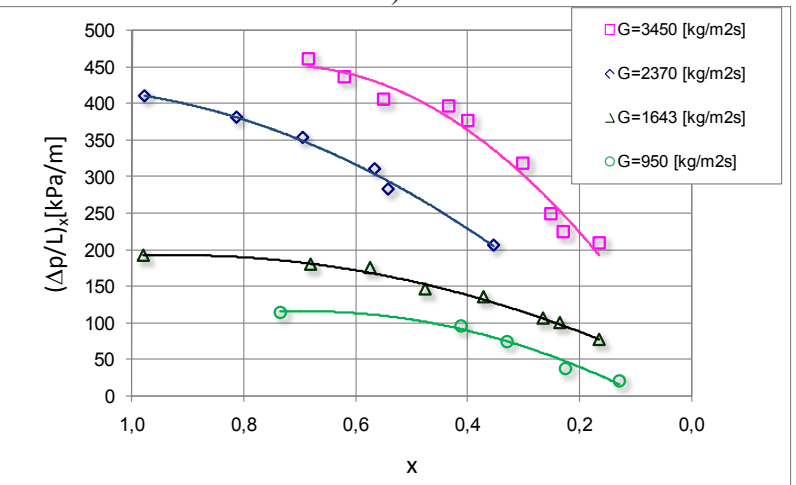

c)

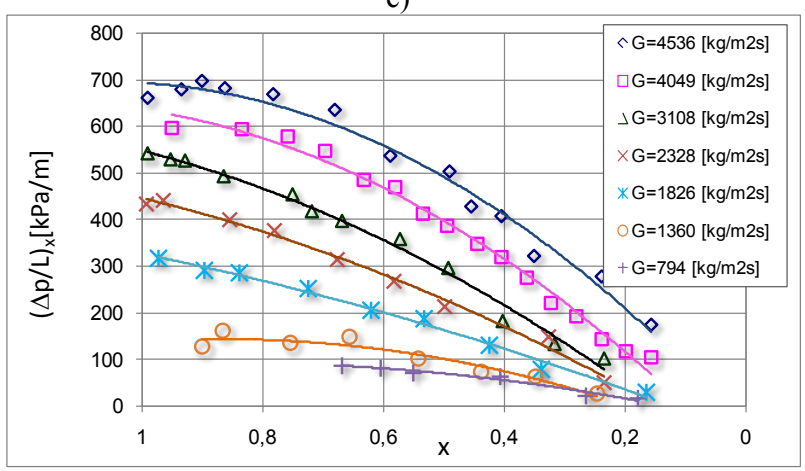

Fig. 6. Local flow characteristics of Novec 649 refrigerant condensation in pipe minichannels a) $\mathrm{d}=0.5 \mathrm{~mm}, \mathrm{~b}) \mathrm{d}=0.7 \mathrm{~mm}$, c) $\mathrm{d}=1.2 \mathrm{~mm}$.

Fig. 7 presents a example dependences of average heat transfer coefficient $\alpha_{\mathrm{a}}$ and average pressure drops $(\Delta \mathrm{p} / \mathrm{L})_{\mathrm{x}}$ on mass flux density for the constant vapour quality $\mathrm{x}=0.6$ during condensation Novec 649 in minichannel with internal diameter $\mathrm{d}=0.7 \mathrm{~mm}$. It showed very brightly dependence of this two heat and flow parameters on the mass flux density G.

a)

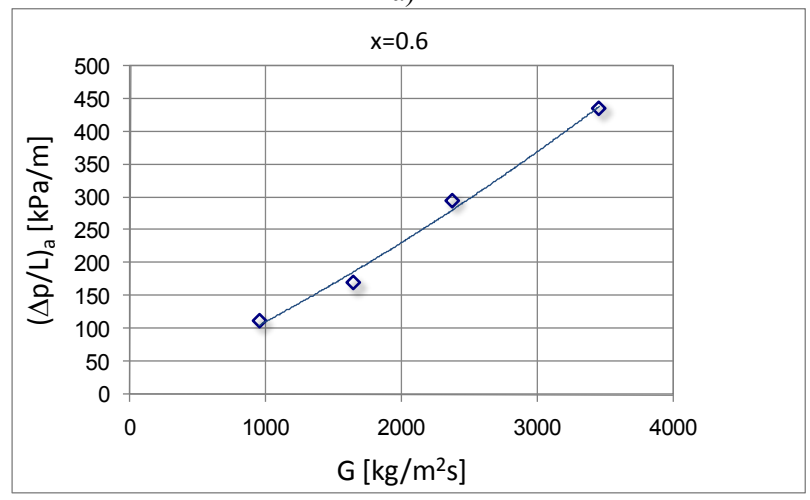

b)

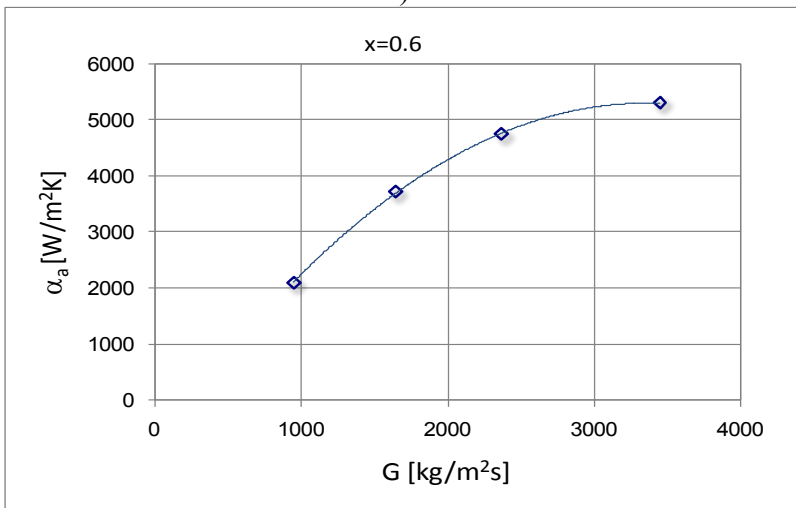

Fig. 7. Average a) flow, b) heat characteristic of Novec 649 refrigerant condensation in minichanal with $\mathrm{d}=0.7 \mathrm{~mm}$.

Own experimental results of the local heat transfer coefficient $\alpha_{x}$ were compared with the calculation results of the correlation of other authors: Shah [18], Akers [2], Thome [22] and Tang end all [21]. Results of this comparison are showed in fig.8 and fig.9.

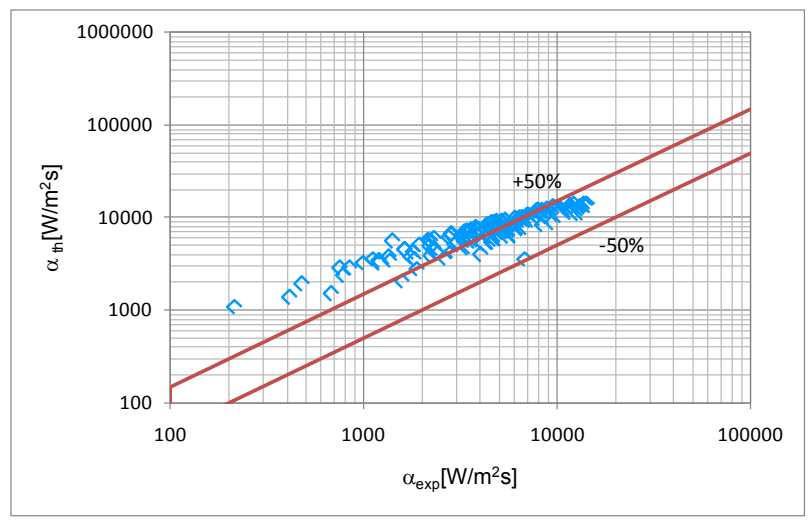

Fig. 8. Comparison of experimental heat transfer coefficient with calculations from correlations of Shah [18]. 
a)

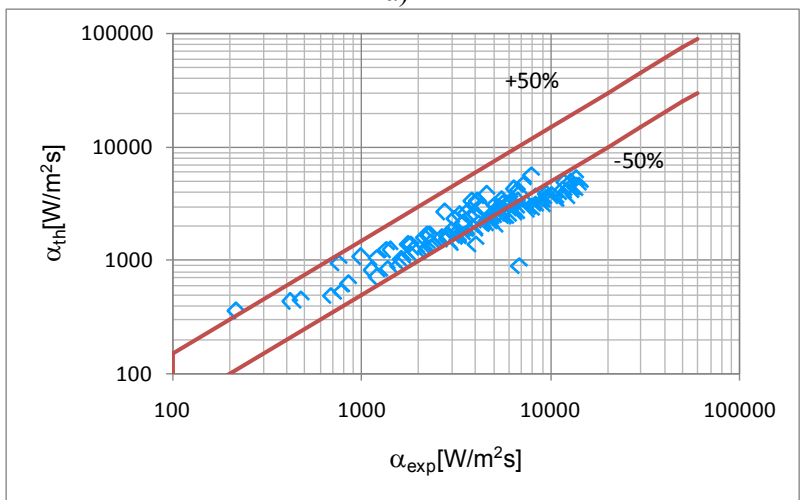

b)

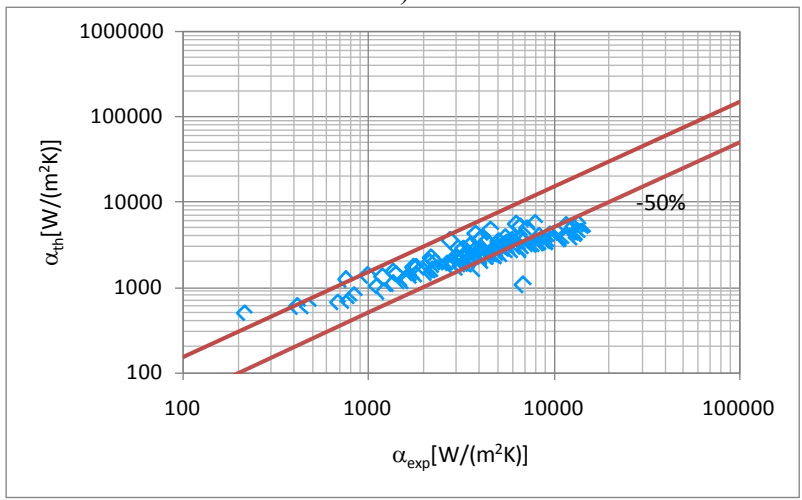

c)

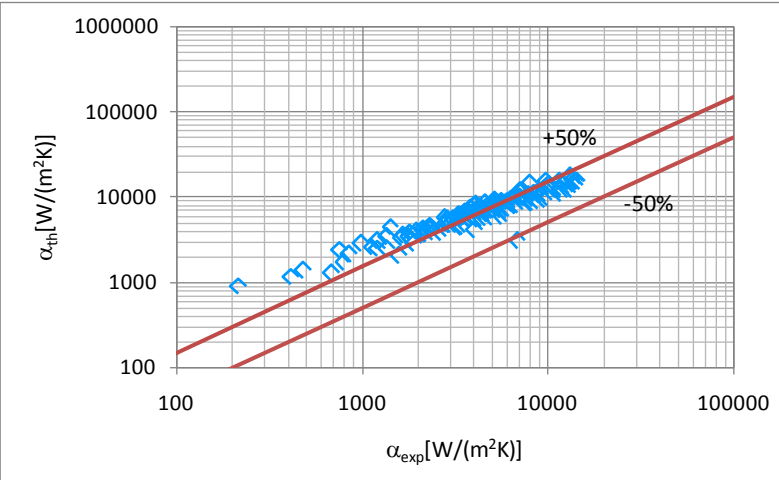

Fig. 9. Comparison of experimental heat transfer coefficient with calculations from correlations of: a) Akers [2], b) Thome [22], c) Tang [21].

The best accuracy of experimental investigation of new refrigerant Novec 649 condensation in minichannels can be observed to the Thome correlation. Unfortunately, in this case the deviation is $50 \%$ which is not a satisfactory result. This may be due to the properties of the refrigerants or the small diameter of the tested channels. This means that more research should be done on the Novec 649 refrigerant, in a larger number of small diameter channels, and then determine the relationship describing the condensation process of this and other similar refrigerants in minichannels.

\section{Conclusions}

1) Pipe mini-channels can be used in the construction of compact refrigeration condensers. In this way heat transfer process during condensation is intensified by a high degree of structural compactness. The heat transfer coefficient is the measure of this intensification compared with conventional channels. The determination of the value of the heat transfer coefficient and the pressure drop during this process constitutes the primary problem for designers.

2) Thermal and flow experimental investigations of Novec 649 refrigerant condensation in pipe minichannels in terms of the channel internal diameter changes is very important. This is the new environmentally friendly refrigerant with low GWP and ODP.

3) Thermal characteristics describing condensing of refrigerants were done, with a description of dependences of local and average heat transfer coefficient, depending on the vapour quality and mass flow density. It is found that the heat transfer coefficient depends on parameters such as thermal parameters of condensation process (saturation temperature), the internal diameter of the tubular minichannel, mass flow density and vapour quality.

4) The thermal characteristics of the tested refrigerant were compared with the results of calculations prepared by other authors. The discrepancies between the experimental results and the calculation results exceeded the range of $\pm 50 \%$, which gives unsatisfactory results and made a new correlation is necessary.

5) There is a need of extension of research with new refrigerants and observation of flow structures, with affect the thermal and flow parameters of the process.

\section{References}

1. R. Akasaka., K. Tanaka, Y. Higashi, Thermodynamic property modeling for 2,3,3,3tetrafluoropropene (HFO-1234yf). International Journal of Refrigeration, vol. 33, 52 - 60, (2010)

2. W. Akers, O.K. Deans, O.K. Crosser, Condensation heat transfer within horizontal tubes. XChem. Eng. Progr., vol. 54, 89-90, (1985)

3. K.J. Bell, M.A. Ghany, An approximate generalized design method for multicomponent partial condenser, AIChE Symposium Series, vol. 69, , pp. 72-79, (1973)

4. T. Bohdal H. Charun, M. Sikora, Eksperymentalne charakterystyki cieplno - przeptywowe skraplania roztworów zeotropowych w kanałach konwencjonalnych $i$ minikanałach. Chłodnictwo, vol. $6,14-19,(2013)$

5. A. Cavallini, , D. Del Col, L. Doretti, M. Matkovic, L. Rossetto, Condensation in horizontal smooth tubes: A new heat transfer model for heat exchanger design, Heat Transfer Engineering. vol. 27(8), pp. 31-38. (2006)

6. A. Cavallini, G. Censi, D. Del Col, L. Doretti L. Rossetto, Heat transfer coefficient HFC refrigerants during condensation at high temperature inside a enhanced tube, Proc. Int. Refrigeration and Air Conditioning Conference, Pardue University, paper 563, R8-2, (2002)

7. J. Coleman, S. Garimella, Two-Phase Flow Regimes in Round, Square and Rectangular Tubes During 
Condensation of Refrigerant R134a, Int. J. of Refrigeration, vol. 26 (1), pp. 117-128, (2003)

8. B.M. Fronk, S. Garimella, In-tube condensation of zeotropic fluid mixtures: A review, Int. Journal of Refrigeration, vol. 36, pp. 534-561, (2013)

9. S. Garimella, Condensation flow mechanisms in microchannels: basis for pressure drop and heat transfer models, Heat Trans. Eng., vol. 25(3), pp. 104-116, (2004)

10. G. Ghim, J. Lee, Condensation heat transfer of low GWP ORC working fluids in a horizontal smooth tube, Int. J. of Heat and Mass Transfer, vol. 104, pp. 718-728, (2017)

11. W. Kuczyński, A. Denis, Modeling the instabilities of the condensation process of the R134a and $R 404 A$ refrigerants in pipe minichannels in the conditions of periodic hydrodynamic disturbances. Journal of Mechanical and Energy Engineering, Vol. 1(41) No. 2, November, pp. 179 - 188, (2017)

12. W. Kuczynski, H. Charun, Modeling of a two-phase region length of the condensation of $R 134 a$ and R404A refrigerants in pipe minichannels with periodic hydrodynamic instabilities. Heat Transfer Engineering, Vol. 35, Issue 9, pp. 850 - 862,

13. W. Kuczyński, Modeling of the propagation of a pressure wave during the condensation process of $R 134$ a refrigerant in a pipe minichannel under the periodic conditions of hydrodynamic disturbances Int. J. of Heat and Mass Transfer, vol. 56, Issue 1-2, pp. $715-723$

14. D. Mikielewicz, R. Andrzejczyk, Comparative study of flow condensation in conventional and small diameter tubes, Archives of Thermodynamics, vol. 33 (2), pp. 67-83, (2012)

15. M. Preißinger, J.A.H. Schwöbel, A. Klamt, D. Brüggemann, Multi-criteria evaluation of several million working fluids for waste heat recovery by means of Organic Rankine Cycle in passenger cars and heavy-duty trucks, Applied Energy, 206, pp. 887-899, (2017)

16. Montreal Protocol on Substances that Deplete the Ozone Layer. drawn in Montreal on September 16, 1987. Dz. U. of December 23, 1992.

17. S. Rajan, Comparison of Refrigerants R410A and R404A for use in low temperature applications: a computer model study, Ph.D. Thesiss, Mechanical Engineering in the Graduate College of the University of Illionois at Urbaba-Champaign, (2011)
18. M.M Shah, A general correlation for heat transfer during film condensation inside pipes, Int. J. of Heat and Mass Transfer, vol. 22, pp. 547-556, (1979)

19. L. Silver, Gas cooling with aqueous condensation, Trans. Inst. Chem. Eng., vol. 25, 1947, pp. 30-42.

20. C.H. Son, H.K. Oh, Condensation pressure drop of R22, R134a and R410A in a single circular microtube, Int. J. of Heat Mass Transfer, vol. 48(8). 1437-1450, (2012)

21. L. Tang, Empirical study of new refrigerant flow condensation inside horizontal smooth and micro-fin tubes, Univeity of Maryland at College Park, Ph.D. Thesis, p. 251, (1997)

22. J.R. Thome, J. El Hajal, A. Cavallini: Condensation in horizontal tubes. New heat transfer model based on flow regimes. Int. J. of Heat and Mass Transfer, vol. 46, p. 3365 - 3387, (2003),

23. J.R. Thome, Condensation in plain horizontal tubes: Recent advances in modeling of the transfer to pure fluids and mixture, J. of the Braz. Soc. Of Mech. Sci.\&Eng.,vol. 27, no. 1, pp. 23-30, (2005)

24. The National Archives. Regulation (EC) No $842 / 2006$ of the European Parliament and of the Council of on certain fluorinated greenhouse gases.

25. Ustawa o postępowaniu $\mathrm{z}$ substancjami zubożającymi warstwę ozonową. Dz. U. nr 52, poz. $537 \mathrm{z}$ dnia 3 marca $2001 \mathrm{r}$.

26. Ch. Wang, System performance of $R-1234 y f$ refrigerant in air-conditioning and heat pump system - An overview of current status. Applied Thermal Engineering, vol. 73, 1 - 9, (2014)

27. J. Wen, X. Gu, S. Wang, Y. Li, J. Tu, The comparison of condensation heat transfer and frictional pressure drop of $R 1234 z e(E)$, propane and R134a in a horizontal mini-channel, Int. J. of Refrigeration, (2018), Accepted Manuscript, DOI 10.1016/j.ijrefrig.2018.03.006

28. H.Y Zhang, J.M. Li, N. Liu, B.X. Wang, Experimental investigation of heat transfer and pressure drop of R22, R410A and R407C in minitubes, Int. J. of Heat and Mass Transfer. Vol.55. pp. 3522-3532, (2012)

29. Zhu X.R. Zhuang, G. F. Chen, X. Zou, Q. L. Song, M.Q.Gong, Experimental investigation on flow condensation of methane in a horizontal smooth tube, Int. J. of Refrigeration, 78, pp.193-214, (2017)

30. www.multimedia.3m.com/mws/media/5698650/3mt m-novectm-649-engeneered-fluid.pdf 